\title{
A Survey on Integrated Wireless Healthcare Framework for Continuous Physiological Monitoring
}

\author{
Mandeep Singh \\ DEC Department, Centre for Development of \\ Advanced Computing, Mohali
}

\author{
Neelu Jain \\ Department of E\&EC, \\ PEC University of Technology, Chandigarh
}

\begin{abstract}
Wireless Body Area Network in recent years has received significant attention, due to their market potential to reduce the healthcare cost as well as load of medical professionals, resulting in higher efficiency. This paper addresses the available wireless body area network prototypes and the issues related to hardware implementations, software and wireless protocols and how smart phones can be used as full featured portable computer in providing healthcare services. These systems are comprised of various types of small physiological sensors ie, ECG, $\mathrm{SpO} 2$ attached to the human body for measuring the physiological parameters and transmit them to remote devices.
\end{abstract}

\section{Keywords}

Wireless Body Area Network (WBAN), Ubiquitous Healthcare (UHC), Saturated Percentage of Oxygen (SpO2), Body Area Network (BAN), Body Sensor Network (BSN), Electrocardiogram (ECG), mHealth (mobile health)

\section{INTRODUCTION}

With the increase in population, the number of patients suffering from diseases is increasing. Thus, there is a need to change from a traditional healthcare system to a pervasive healthcare, where continuous/real time monitoring enables an early detection of a disease and allows for proactive action as defended by Kulkarni and Gupta [1,2]. Recent advances in electronics introduce the concept of using wireless body area network (WBAN) technologies near/ around the human body anytime anywhere. WBANs consist of smart miniaturized, lightweight, ultra low-power devices attached to the human body (motes) that are able to sense, process and communicate. These sensors can be either wearable or implanted, where wearable devices can be used on the body surface of the user and the implantable medical devices are inserted inside human body to monitor physiological signals. The physiological parameters are then transmitted to the medical server without much disturbance to the daily routine of the patient. Such systems are found to be suitable for supervision of high risk populations, outpatients, elderly people and health conscious people.

\section{PRIOR WORK}

Recently, a lot of research is going on in the field of pervasive healthcare and telemedicine where wireless healthcare systems are driving the demand for smart and connected devices. In this section several types of developed health monitoring systems are discussed based on the commercial products or research prototypes alongwith their hardware configuration.

Ubiquitous Healthcare (UHC) Monitoring System, designed by Bourouis et al., [3] using components based system architecture provides services for the elderly people. In this architecture accelerometer as Intelligent Central Node (ICN) is used that monitors real time health status using Bluetooth in WBAN and smart phones via internet accessibility.
WBAN architecture using wearable smart shirt, based on UHC (Ubiquitous healthcare) and activity monitoring is proposed by Lee et al., [4]. This architecture comprises of multi-hop sensors in smart shirt having Universal Serial Bus (USB) programming board as a separate module. The size of integrated wearable sensor nodes is reduced by mounting the device on two process control blocks.

Alemdar and Ersoy [5] investigated major benefits and challenges of wireless healthcare systems alongwith design considerations like unobtrusiveness, scalability, energy efficiency, security and comprehensive analysis.

One of the major issues in sensor networks is to utilize the energy efficiently. Mirak et al., [6] proposed distributed energy efficient algorithm specially for efficient energy utilization in which sensors should be deployed in optimized manner. Algorithm for solving the problem of complete coverage with minimum cost is proposed by Osmani [7] and it describe different sensor placement techniques for analyzing the efficiency of sensor network.

Pawar et al., [8] proposed the framework for comparing mobile patient monitoring systems by aiming both healthcare professionals and computer professionals. For healthcare professionals, this paper provides technical aspects and highlights a number of issues implied by the use of these systems and for computer professionals it benefits by gaining an understanding of the latest software developments.

Periera et al., [9] presents a Windows Mobile based system for body parameters monitoring. The proposed system comprises a SHIMMER-based body sensor network used to measure and collect body temperature through a windows mobile application for personal monitoring. The communication between the sensor and the mobile device is performed over a Bluetooth connection.

Pantelopoulos and Bourbakis [10] evaluate the systems based on certain physiological parameters along with a description of their communication modules and hardware. Finally, an overall maturity score was set for every system and none of the systems achieve the maximum maturity level.

Yuce [11] describes the employment of wireless body area networks in medical environment. The system is designated to operate in a medical centre for multi patient monitoring. The body parameters ie. Pulse rate, temperature, and ECG are transmitted to the CCU (Central Control Unit) connected to the personal computer using MICS (medical implant communication service) and WMTS (wireless medical telemetry service) wireless technologies. The data collected at the local PC is transferred through internet to a remote PC in a medical centre. The size of sensors developed is $7.5^{*} 7.8 \mathrm{~cm}$ with $17.53 * 17.53 \mathrm{~cm} \mathrm{CCU}$ board using PIC16F887. It can be seen that the size of the developed system needs to be reduced to make it wearable and comfortable. 
Table 1 gives a comparison of various prototypes developed along with their corresponding measured physiological signals. The measurement of these vital biosignals leads to estimate overall user's health condition at any given time by collecting real-time physiological parameters and their subsequent processing for feature extraction.

Table 1: Comparison of sensing prototypes developed

\begin{tabular}{|c|c|c|c|c|c|}
\hline $\begin{array}{c}\text { Project } \\
\text { Title(Institution) }\end{array}$ & $\begin{array}{l}\text { Hardware } \\
\text { description/power } \\
\text { requirement }\end{array}$ & $\begin{array}{c}\text { Communication } \\
\text { Modules }\end{array}$ & $\begin{array}{l}\text { Measured } \\
\text { Signals }\end{array}$ & $\begin{array}{c}\text { Medical } \\
\text { Applications }\end{array}$ & Comments \\
\hline $\begin{array}{c}\text { LiveNet (MIT } \\
{[12]}\end{array}$ & $\begin{array}{l}\text { PIC based SAK2 } \\
\text { data acquisition } \\
\text { board, uses } 3.3 \mathrm{~V} \\
\text { and } 5 \mathrm{~V} \text { regulated } \\
\text { power }\end{array}$ & $\begin{array}{l}\text { Wires, } 2.4 \mathrm{GHz} \\
\text { radio, GPRS }\end{array}$ & $\begin{array}{l}\text { ECG, } \\
\text { EMG, } \\
\text { GSR }\end{array}$ & $\begin{array}{c}\text { Epilepsy seizures } \\
\text { detection and } \\
\text { behavior } \\
\text { modeling }\end{array}$ & $\begin{array}{c}\text { Consumes more } \\
\text { Power }\end{array}$ \\
\hline $\begin{array}{l}\text { Magic (Univ. Of } \\
\text { Milan, Bioeng, } \\
\text { Centre \& cardiac } \\
\text { Rehab. Unit) }\end{array}$ & $\begin{array}{l}\text { Vest with Textile } \\
\text { Sensors }\end{array}$ & Bluetooth & ECG & $\begin{array}{c}\text { Recording of } \\
\text { Cardiac signals on } \\
\text { PC }\end{array}$ & $\begin{array}{l}\text { Data shows good } \\
\text { quality of signal most } \\
\text { of the time }\end{array}$ \\
\hline $\begin{array}{c}\text { Smart Vest } \\
\text { (National pr. on } \\
\text { Smart Materials, } \\
\text { India) [14] } \\
\end{array}$ & $\begin{array}{l}\text { Vest with woven } \\
\text { sensors using } \\
\text { microcontroller }\end{array}$ & Woven wires & $\begin{array}{c}\text { ECG,T, } \\
\text { BP }\end{array}$ & $\begin{array}{l}\text { General Health } \\
\text { monitoring }\end{array}$ & $\begin{array}{c}\text { Motion artifacts and } \\
\text { base line wander } \\
\text { gives inaccurate } \\
\text { readings }\end{array}$ \\
\hline $\begin{array}{c}\text { Personal health } \\
\text { Monitor (Un. Of } \\
\text { Tech. Sydney) [15] }\end{array}$ & Biosensors & $\begin{array}{l}\text { Bluetooth, } \\
\text { Biosensors }\end{array}$ & ECG & $\begin{array}{l}\text { Heart attack self } \\
\text { test using nokia } \\
\text { mobile }\end{array}$ & $\begin{array}{l}\text { Not } 100 \% \text { accurate } \\
\text { system as it gives } \\
\text { false information } \\
\text { about heart attack }\end{array}$ \\
\hline $\begin{array}{c}\text { Design of } \\
\text { Environments for } \\
\text { ageing [16] }\end{array}$ & $\begin{array}{l}\text { Atmega } 1284 \mathrm{p} \text { based } \\
\text { hardware, uses } 3.3 \mathrm{~V} \\
\text { and } 5.5 \mathrm{~V} \text { supply }\end{array}$ & Bluetooth & ECG,T & $\begin{array}{c}\text { For self } \\
\text { monitoring using } \\
\text { wrist based watch }\end{array}$ & $\begin{array}{l}\text { Consumes more } \\
\text { power }\end{array}$ \\
\hline
\end{tabular}

A lot of manufacturers like Nonin [17], Philips [18], Nellcor [19], Redding Medical [20], and others are providing commercially available sensors for health monitoring. Other examples are the heart rate monitors manufactured from polar and Blood pressure machine from Omron for display of vital measurements.

Though the above systems use new innovative sensors, but they disturb the user mobility and comfort and lack in terms of the number of vital parameters being monitored. New and interactive ways of communication between patients and healthcare providers can reduce the health-worker to patient ratio. Smartphone applications and replacing the available sensors with the low cost, miniaturized healthcare sensors proved to the vital tools in low cost healthcare management.

\section{SMARTPHONE BASED WBAN}

\section{HEALTHCARE SENSOR FRAMEWORK}

Currently increase in demand of smartphones and its exposure with $3 \mathrm{G}$ and $4 \mathrm{G}$ boost the adoption of healthcare systems rapidly. Thus there is a need to design, develop and integrate the low cost healthcare sensors with smartphones which can make healthcare accessible to anyone, anytime, and anywhere by eliminating constraints such as time, location. A typical example of mobile based WBAN structure using smartphones for monitoring real time physiological parameters is shown in Figure 1. A WBAN is heterogeneous in nature and may include many devices ie. ECG, Blood Pressure, SpO2 etc. collectively attached to the body and has the characteristics of general wireless sensor networks.

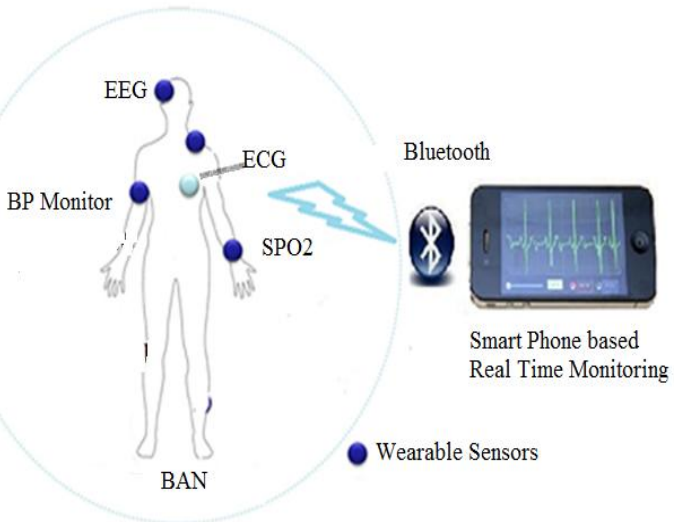

Fig 1: WBAN Healthcare Sensor Framework

The WBAN is formed by three types of modules:

\subsection{Module1: Vital Physiological Parameters Monitoring Device}

This section provides a summary of various sensor technologies which can be integrated as a part of wireless health-monitoring systems along with their typical uses in Table 2.

The detail of the sensing technologies along with their measuring methods is given below:

\subsubsection{ECG Sensor node:}

Currently most of the telemedicine systems involve ECGs with 12-15 leads. Usually electrodes are fixed on a patient's chest, both arms and the right leg, and sense the cardio- 
rhythms and electrical impulses in a short time period. However attaching a number of electrodes makes patients uncomfortable during the examinations and this type of cardiac examination takes more than 30 minutes. To avoid these difficulties, a continuous wireless ecg is required to be developed which would be wearable and utilise minimum number of electrodes with low power consumption.

\subsubsection{Blood Pressure node:}

Blood pressure systems are based on Oscillometry method or PTT (Pulse Transit Time) method. Generally cuff based sensors employ a pressure cuff, pump and transducer to measure blood pressure in three phases: Inflation, Measurement, and Deflation. Cuffless type machines are used in ICU (Intensive Care Unit) where blood pressure is calculated by measuring Pulse Transit Time from ECG and PPG (Photoplethysmography) sensors. It is very important parameter for cardiac patients.

\subsubsection{Integrated blood oxygen saturation, heart rate and skin temperature node:}

Pulse oximeters measure arterial blood oxygen saturation by sensing absorption properties of deoxygenated and oxygenated hemoglobin using PPG (Photoplethysmography). A basic meter comprised of a red and IR sensors attached to a patient's earlobe, toe, finger or other body locations and data acquisition system for the calculation and display of oxygen saturation level, heart rate and blood flow. It is recommended during surgery and post trauma care.

\subsection{Module2: Wireless Communication Standards for WBAN}

Figure 1 illustrates transmission of physiological parameters from the biosensors to the mobile phone. In the overall context of transmission of data, it can be handled either by wires or by multiple wireless links. Wires hindered the user's mobility and comfortableness and moreover there is an increased risk of system failure. A more favorable approach to this matter is the use of some integrated type of flexible autonomous wearable wireless sensors to transmit the parameters collected from sensors. Table 3 gives the details of the various unlicensed wireless healthcare standards. To make the power consumption and size of the device low, short range device Zigbee and Bluetooth are used.

\subsection{Module3: Software development Phase for WBAN:}

Software has a well defined interface to integrate hardware and application programs. During software development phase the designer has a choice of programming platforms for improving software productivity. Software includes three levels: firmware, operating system, application software stacks. Operating system used by designer for developing mobile phone based applications can be Android OS, Blackberry OS, Windows mobile OS and apple iOS etc. The most preferred mobile devices today are based on Android and apple iOS operating systems. Each of these operating system developers and users are constantly trying to outdo the other.

Table2: List of Physiological Parameters

\begin{tabular}{|c|c|c|c|c|c|c|}
\hline $\begin{array}{l}\text { Sr. } \\
\text { No }\end{array}$ & Sensor & $\begin{array}{l}\text { Measurement } \\
\text { Method }\end{array}$ & Functionality & $\begin{array}{c}\text { Traditional } \\
\text { Measuring Method }\end{array}$ & $\begin{array}{c}\text { Emerging } \\
\text { Technologies }\end{array}$ & $\begin{array}{c}\text { Current } \\
\text { prices(wireless } \\
\text { Bluetooth Based } \\
\text { Sensors) }\end{array}$ \\
\hline 1 & $\begin{array}{l}\text { Electrocardiogram } \\
\text { (ECG) }\end{array}$ & Noninvasive & $\begin{array}{l}\text { Electrical } \\
\text { activity of heart }\end{array}$ & $\begin{array}{l}\text { 12-Leads and ECG } \\
\text { machine }\end{array}$ & $\begin{array}{l}\text { 1-Lead, 3-Lead } \\
\text { and 5-Lead ECG }\end{array}$ & $\begin{array}{c}\text { Schimmer } \$ 147 \\
\text { Alivecor } \$ 199\end{array}$ \\
\hline 2 & $\begin{array}{l}\text { Blood pressure } \\
\text { (Systolic \& } \\
\text { Diastolic ) }\end{array}$ & Noninvasive & $\begin{array}{l}\text { Arterial pressure } \\
\text { measurement }\end{array}$ & Sphygmomanometer & $\begin{array}{l}\text { Determination } \\
\text { using red and } \\
\text { infrared light } \\
\text { passing through } \\
\text { pulsating blood in } \\
\text { vascular tissue. }\end{array}$ & ihealth $\$ 99.75$ \\
\hline 3 & Oxygen saturation & Noninvasive & $\begin{array}{l}\text { Indicates the } \\
\text { amount of } \\
\text { oxygen in } \\
\text { patient's blood }\end{array}$ & $\begin{array}{l}\text { Lancets, Test strips } \\
\text { and Oximeter }\end{array}$ & $\begin{array}{l}\text { The red LED } \\
\text { measures } \\
\text { deoxygenated } \\
\text { hemoglobin and } \\
\text { the infrared LED } \\
\text { measures } \\
\text { oxygenated } \\
\text { hemoglobin }\end{array}$ & CMS-50E \$106 \\
\hline 4 & Heart rate & Noninvasive & $\begin{array}{l}\text { Frequency of } \\
\text { cardiac cycle }\end{array}$ & Stethoscope & Acoustic Sensors & CMS-50E \$106 \\
\hline 5 & $\begin{array}{l}\text { Skin } \\
\text { temperature }\end{array}$ & Noninvasive & $\begin{array}{l}\text { Measure of } \\
\text { body's ability to } \\
\text { generate and get } \\
\text { rid of body heat }\end{array}$ & $\begin{array}{l}\text { Thermometer- } \\
\text { typically mercury or } \\
\text { alcohol based }\end{array}$ & $\begin{array}{l}\text { Non-touch } \\
\text { infrared based } \\
\text { digital } \\
\text { thermometer }\end{array}$ & NA \\
\hline 6 & Serum Glucose & Invasive & $\begin{array}{l}\text { Measure serum } \\
\text { glucose level }\end{array}$ & $\begin{array}{l}\text { Lancets, Test strip } \\
\text { and Glucose meter }\end{array}$ & $\begin{array}{l}\text { Based on thermal } \\
\text { emission } \\
\text { spectroscopy }\end{array}$ & NA \\
\hline
\end{tabular}


Table 3: Healthcare Wireless Standards

\begin{tabular}{|l|l|l|l|l|}
\hline $\begin{array}{l}\text { Wireless } \\
\text { Standard }\end{array}$ & Range & $\begin{array}{c}\text { Data } \\
\text { rate } \\
\text { (max). }\end{array}$ & $\begin{array}{c}\text { Power } \\
\text { consumed }\end{array}$ & Frequency \\
\hline Zigbee & $\begin{array}{l}10- \\
75 \mathrm{~m}\end{array}$ & $\begin{array}{l}20 \mathrm{kbps} / \\
40 \mathrm{kbps} / \\
250 \mathrm{kbps}\end{array}$ & $30 \mathrm{~mW}$ & $\begin{array}{l}868 \mathrm{MHz} / 91 \\
5 \mathrm{MHz} / 2.4 \\
\mathrm{GHz}\end{array}$ \\
\hline Bluetooth & $\begin{array}{l}10- \\
100 \mathrm{~m}\end{array}$ & $\begin{array}{l}1- \\
3 \mathrm{Mbps}\end{array}$ & $\begin{array}{l}2.5- \\
100 \mathrm{~mW}\end{array}$ & $2.4 \mathrm{GHz}$ \\
\hline IrDA & $1 \mathrm{~m}$ & $16 \mathrm{Mbps}$ & & Infrared \\
\hline $802.11 \mathrm{~g}$ & $200 \mathrm{~m}$ & $54 \mathrm{Mbps}$ & $1 \mathrm{~W}$ & $2.4 \mathrm{GHz}$ \\
\hline
\end{tabular}

\section{ISSUES OF WBAN}

The developer of the wireless medical devices compared to stationary equipment has to take additional user requirements into account. Also, instead of first designing a functional prototype and then making it wearable both tasks need to be tackled concurrently, in order to avoid costly redesigns. In this section discuss open research problems in WBAN are discussed and some potential solutions are suggested.

Small and light weight: In general a lot of biosensors used in current healthcare systems tend to have bulky size and may require very specific on body placement or body postures to provide reliable measurements. Further improvement in advanced sensor design and miniaturization is required to appropriately address these shortcomings.

Low power: Power consumption appears to be the biggest technical issue and performance bottleneck in current implementations. Biosensor systems should be able to operate maintenance free for long periods. Further research in power scavenging techniques, low power transceivers and improvements in battery technologies promise to solve this problem.

Reliable communication in WBANs is of utmost importance for medical applications and it could be dangerous or even fatal for false readings to appear on a patient's monitor output. Medical sensors vary with required sampling rates, from less than $1 \mathrm{~Hz}$ to $1000 \mathrm{~Hz}$ and these are subject to very sensitive information about patients. One approach to improve reliability is to perform on-sensor signal processing where instead of transferring raw data from a sensor, we can transfer only particular information about a event by performing feature extraction on the sensor.

Sensors: Novel applications depend on new sensor concepts, which cannot easily be integrated into standard electronics or housings. Also, where direct physical contact with the user is required, biocompatibility issues may influence the sensor principles and signal post-processing. The biosensors used, need to be unobtrusive in order to be worn as a daily accessory without looking like a medical device.

Interoperability: Wireless medical sensors must have the capability to integrate different types of medical services and should allow users to easily assemble a robust WBAN depending on the user's state of health. This promotes vendor competition that would eventually result in more affordable systems.

Interference: There is the possibility of interference that might come from other types of wireless communication or

Bluetooth devices or in some cases some EM devices operating in the vicinity. It is clear that information from one person's network should not manifest itself on someone else's display system. Different mechanisms should be adopted to ensure robustness and to make sure that data frames gets through to the correct receiver without collisions or other errors.

Bandwidth: There is a direct relationship between frequency and tissue warming, the higher the frequency of the EM signal, the higher is its absorption by the tissue and more the tissue warming [21]. The frequency range selected for communications plays an important role in the design and performance; hence it is desirable to use lower frequencies for communications. To avoid excessive radio interference, it may be advisable to use the designated, unlicensed ISM (Industrial, Scientific and Medical) frequency bands .

Data Rate Capacity: How much data is possible to transfer per unit of time between the nodes and the mobile phone in a sensor network is of importance.

Real Time Synchronization: The ability of the network to transmit data in real time, without error, is important in this project. Time synchronization between sensors and mobile phone in BAN needs to work seamlessly.

Security: The security in wireless networks is always of great importance. In sensor networks it is especially important to have integrity and authentication. Integrity means that the data at the receiver is the same as at the sender and has not been accidentally or maliciously modified, altered, or destroyed. Authentication is a concept within computer security that means to make absolute sure that the sender really is who it claims to be.

Cost: To be able to compete in the international market it is essential that the components are at lowest possible price. This is very important when the product is mass-produced.

\section{CONCLUSION AND FUTURE SCOPE}

This paper reviewed continuous health monitoring based on the state-of-the-art research and development of wireless sensor-based systems. The study shows that WBAN has the potential to revolutionize healthcare by providing low-cost solutions. In future there are still a lot of challenges and issues that need to be resolved as discussed above for wireless healthcare systems. Based on the macro-trends and current market interests, it is concluded that there is a need to develop/integrate low cost wireless healthcare sensors (ECG, BP, SpO2, Body Temperature) which are easy-to-use, reliable, minimally obtrusive, multifunctional and accepted by patients and other users. Use of smart phone applications based devices is expected to revolutionize the mHealth market by improving healthcare delivery and dissemination of medical information. It can be seen that Android dominates the $81 \%$ of the world smart phone market and WBAN designed using android based phones serves as a alternative to expensive hospital medical equipments and has the potential to reduce the per capita cost of healthcare, while simultaneously maintaining or improving quality of health care. 


\section{REFERENCES}

[1] Kulkarni, P. and Ozturk, Y. 2007. Requirements and Design Spaces of Mobile Medical Care. Journal of ACM Sigmobile Mobile Computing and Communication Review. Vol.11, No.3, pp. 12-30.

[2] Gupta, S. K. S. 2008. Safe and dependable bio-sensor networking for pervasive healthcare. Dept. Computer Science, Arizona State University, http://impact. asu. edu/ mcn/Presentations/AYUSHMAN BIOMED ASU Jan 2008 FINAL. ppt.

[3] Bourouis, A., Feham, M., \& Bouchachia, A. 2011. Ubiquitous Mobile Health Monitoring System for Elderly (UMHMSE). International Journal of Computer Science and Information Technology (IJCSIT), Vol. 3 No. 3, pp. 74-82.

[4] Lee, Y. D. and Chung, W. Y. 2009. Wireless Sensor Network Based Wearable Smart Shirt for Ubiquitous Health and Activity Monitoring. Journal of Sensors and Actuators B: Chemical, Vol. 140, Issue2, pp. 390 -395.

[5] Alemdar, H. and Ersoy, C. 2010. Wireless sensor networks for healthcare: A survey. Journal of Computer Networks, Vol. 54, pp. 2688-2710.

[6] Mirak, H.T. Sabaei, M. Sabooniha, M. 2012. A Distributed Algorithm for Coverage Management in Wireless Sensor Networks. Journal of Basic and Applied Scientific Research, Vol. 2 No.11, pp. 11063-11070.

[7] Osmani, A. 2012. Design and Evaluation of New Intelligent Sensor Placement Algorithm to Improve Coverage Problem in Wireless Sensor Networks. Journal of Basic and Applied Scientific Research, Vol. 2 No.2, pp.1431-1440.

[8] Pawar, P. Jones, V. Van Beijnum, B. J. F. and Hermens, H. 2012. A Framework for the Comparison of Mobile Patient Monitoring Systems. Journal of Biomedical Informatics, Vol. 45 pp. 544-556.

[9] Pereira, O. R. Caldeira, J. M. Shu, L. \& Rodrigues, J. J.2013. An efficient and low cost Windows Mobile BSN Monitoring System Based on TinyOS. Journal of Telecommunication Systems, Vol. 54. Issue 1, pp. 1-9.

[10] Pantelopoulos, A., \& Bourbakis, N. G. 2010. A Survey on Wearable Sensor Based Systems for Health Monitoring and Prognosis. IEEE Transactions on Systems, Man and Cybernetics, Vol.40 No.1, pp. 1-12.
[11] Yuce, M. R. 2010. Implementation of wireless body area networks for healthcare systems. Sensors and Actuators A: Physical, Vol. 162 No.1, pp.116-129.

[12] Sung, M. Marci, C. and Pentland, A. 2005. Wearable Feedback Systems for Rehabilitation. Journal of Neuro Engineering and Rehabilitation, Vol. 2 No. 17, pp. 1-12.

[13] Di Rienzo, M., Rizzo, F., Parati, G., Brambilla, G., Ferratini, M., and Castiglioni, P. 2005. MagIC system: A New Textile-based Wearable Device for Biological Signal Monitoring Applicability in Daily Life and Clinical Setting. In Proceeding of 27th International IEEE Engineering in Medicine and Biology Conference 2005, Shangai, China, pp. 7167-7169.

[14] Pandian, P. S. Mohanavelu, K. Safeer, K. P. Kotresh, T. M. Shakunthala, D. T. Gopal, P. and Padaki, V. C. 2008 Smart Vest: Wearable Multiparameter Remote Physiological Monitoring System. Journal of Medical Engineering and Physics, Vol. 30, pp. 466-477.

[15] Leijdekkers, P. and Gay, P. 2008. A self-test to detect a heart attack using a mobile phone and wearable sensors: In Proceedings of 21st IEEE International Symposium on Computer-Based Medical Systems 2008, University of Jyvaskyla, Finland, pp. 93-98.

[16] Chin, C. A., Crosby, G. V., Ghosh, T., \& Murimi, R. 2012. Advances and Challenges of Wireless Body Area Networks for Healthcare Applications. In Proceedings of the IEEE Workshop on Computing, Networking and Communications 2012, University of Bundeswehr Munchen, Germany, pp. 99-103.

[17] Nonin. [online] http://www.nonin.com (Accessed 15 July 2013)

[18] Philips Healthcare. [online] http://www. healthcare.philips.com (Accessed 6 October 2013).

[19] Nellcor. [online] http://www.nellcor.com (Accessed 15 September 2013).

[20] Redding Medical. [online] Available: http://www.reddingmedical.com (Accessed 6 October 2013).

[21] Vahidi,V. Alighanbari, A. Haghnegahdar, A. 2012. Evaluation of Several Sensor Placement Scenarios and Positioning Methodologies in Wireless Sensor Networks. Journal of Basic and Applied Scientific Research, Vol.2 Issue11, pp. 10945-10950 